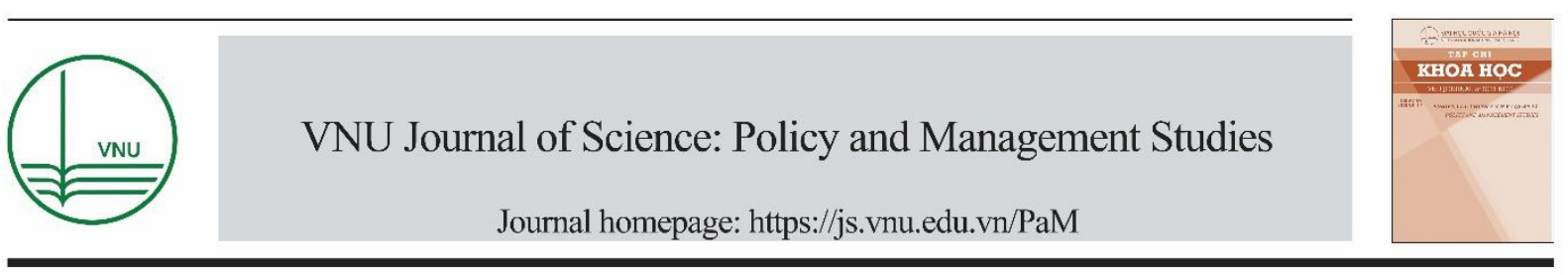

Original Article

\title{
Sustainable Development and Social, Ecological, and Economic Transformation in Vietnam: Insights for Policy
}

\author{
Joachim H. Spangenberg* \\ Sustainable Europe Research Institute SERI Germany, Vorsterstr. 97, 51103 Cologne, Germany,
}

Received 22 June 2019

Revised 23 June 2019; Accepted 23 June 2019

\begin{abstract}
Vietnam is at crossroads: being a middle income country now, it has to deal with social, economic and environmental challenges better known from affluent countries, while still being in the transition from an agricultural to an industrial in a society transiting from rural to urban. At the same time, Vietnam has to prepare for the diverse impacts of climate change, a process beyond its control, by developing adaptation measures safeguarding the social and environmental basis of the society and economy. This requires strategic planning with a focus on enhancing the resilience of economy and society; supporting differentiation and diversity is a core element of this, in rural as much as in urban settings. Current policies need to be updated to accommodate both the value of diversity, and the long term perspective required to mitigate climate change impacts.
\end{abstract}

Keywords: Vietnam, Social Ecological and Economic Transformation, polarisation, industrialisation, urbanisation, market risks, environmental threats

\section{Introduction}

Vietnam has made remarkable progress, socially and economically, over the last decades. Those past successes are a source of confidence that it will be able to meet future challenges just alike, but in order to do so a clear recognition of what the challenges are, where established

\footnotetext{
*Corresponding author.

E-mail address: Joachim.Spangenberg@gmail.com
}

_https://doi.org/10.25073/2588-1116/vnupam.4160 business as usual practices will help, and where they will fail solving the upcoming problems.

The UN Sustainable Development Goals, which Vietnam has adopted and supported [1], give a first hint of how broad the problems are (see figure 1). For instance, Vietnam has been enjoying an extended period of peace (SDG 16), and has been actively searched for partnerships on the international stage (the recent free trade 
agreement with the EU being just one example SDG 17). Industry, innovation and infrastructure have made remarkable progress (SDG 9) and economic growth has been impressive (SDG 8; although there is room for improvement regarding decent work). Zero hunger (SDG 2) is almost achieved, and the progress towards SDG 1 , No Poverty, is remarkable.

However, health and well-being (SDG 3), quality education (SDG 4), gender equality (SDG 5), affordable and clean energy (SDG 7), reduced inequalities (SDG 10) and climate action (SDG 13) have not kept pace with the rapid economic development [2-4].

Unfortunately, there are even negative developments being found, related for instance to clean water (SDG 6), sustainable cities and communities (SDG, 11), responsible consumption and production (SDG 12), and life below water (SDG 14) and on land (SDG 15) [5-8].

This uneven progress shows clearly which achievements to celebrate and to consolidate, but also where improvements are required. Unlike countries in a settled, if not static situation, Vietnam has to accommodate all these objectives during multiple overlapping transition and transformation processes. While this is an obstacle given the limited human, economic and physical resources at hand, it is also an opportunity: it is easier to modify existing dynamics than starting major transformations from a static situation [9].

Vietnam is confronted with a number of interacting transitions and their implications, from a poor to a middle income and from an agricultural to an industrialised economy, from a rural to an urbanised population distribution, from a planned to a socialist market economy, and from a rather steady state to a rapidly changing climate (increasing typhoon frequencies and strength, rising sea level, biodiversity loss, environmental pollution), on top of multiple existing environmental problems like water pollution which links back to issues of life below water and on land and inequalities (environmental justice), but also to food safety and health and well-being. This illustrates that marginal changes in specific domains will not be enough, but a systemic approach is required.

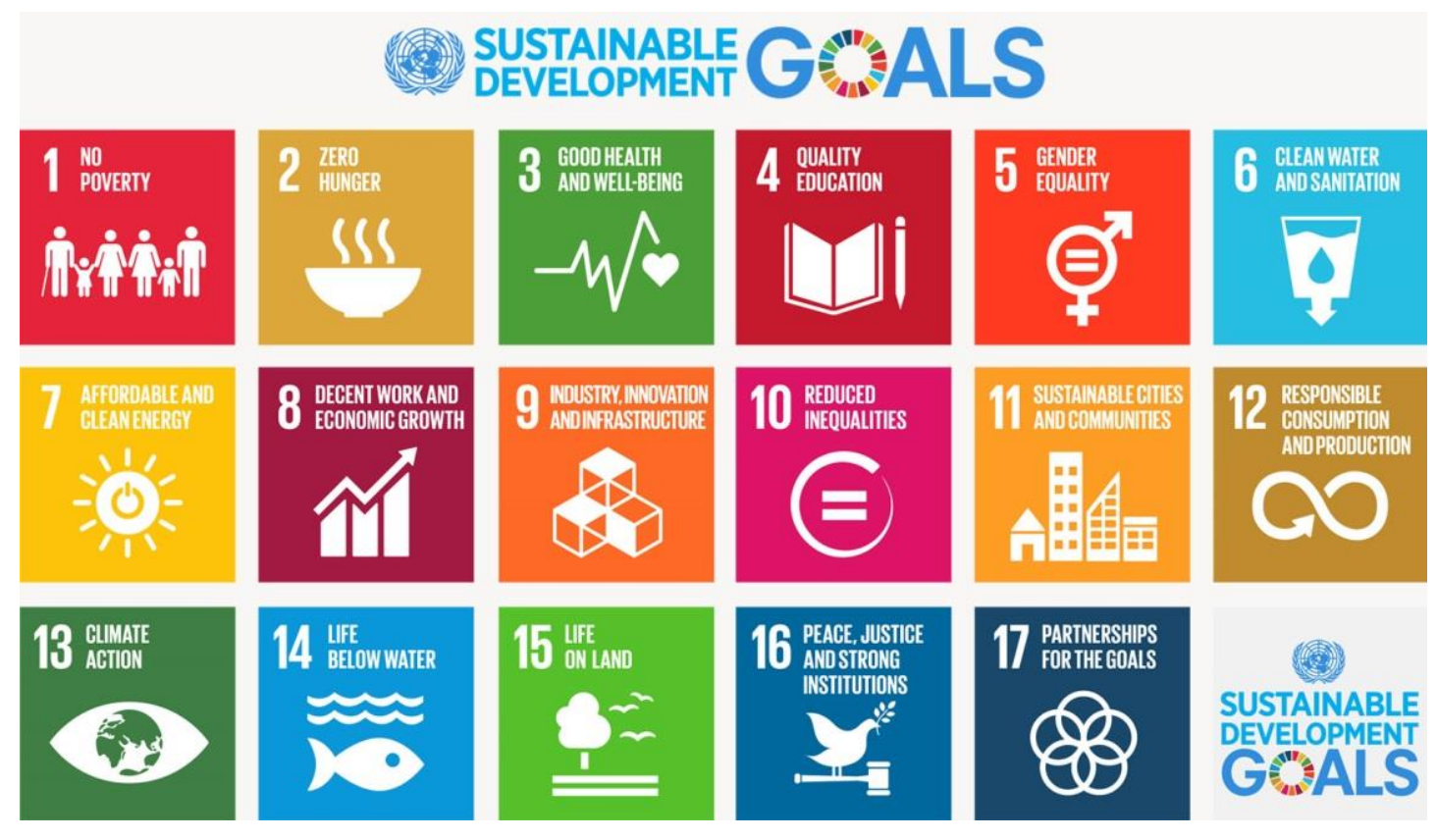

Figure 1. The Sustainable Development Goals, part of the UN 2030 Agenda. 


\section{Transformations}

\subsection{From a poor to a middle income country}

While the ongoing eradication of poverty is highly welcome to everybody, the benefits of economic growth have been distributed unevenly - as it is usually the case in market economies in the absence of counterbalancing policy interventions [10]. While over the two decades 1992-2012 the annual average consumption growth was still remarkable $4.8 \%$ for the lowest income decentile, it was $5.9 \%$ for the fifth and $6.3 \%$ for the top decentile [4]. Smallholder farmers in Northern Vietnam and ethnic minorities are amongst those who have gained least, while urban elites and large scale farmers in the Mekong are among the winners.

The result are increasing social tensions which cannot for ever be pacified with the promise of future economic growth, as the disadvantaged remember the below average benefits they had from past growth and see the social gaps widening. Hence redistribution of income and wealth can be expected to become a condition of social peace over the next decade. Furthermore, increasing wealth causes increasing energy demand, which Vietnam so far meets by building additional coal fired power plants. However, their emissions contribute not only to climate change which will hit Vietnam more harshly than most other countries in the world (see below), they are also one main reason for urban air pollution, particulate matter, health impacts and imping on the life expectancy at birth, let alone the health life expectancy. Recent efforts to build nuclear capacity in collaboration with Russia [11] are counterproductive for a zero carbon energy system as nuclear plants require a different grid from those catering decentralised renewable energy - the cost of restructuring in Germany are estimated to reach 7 billion Euro by 2030 [12].

Another issue of increased consumption is private cars, which do not only contribute to climate change (in Germany $18 \%$ of all greenhouse gas emissions, and - as the only sector - increasing) [13] and as durable objects, like the power plants, determine higher emissions for an extended period of time. They also cause infrastructure demand endangering biodiversity [14], accidents causing significant social cost, and reduce the inhabitability of cities (see below, urbanisation). Thus the government should discourage private car ownership, for instance by banning all private cars in the inner cities as 'Zone à Circulation Restreinte' (in the countryside, they offer serious benefits, given the lack of alternatives).

Finally, Vietnam must continue the process of economic diversification, if only to balance the risks of an increasingly volatile world market. Given this high demand for jobs, one option is luring even more low productivity, job creating productions to Vietnam (the US-China trade conflict may offer opportunities). However, in a medium-term perspective, it is decisive not to get stuck at the low end of the value adding chains, but use it as an entry point for higher value added production (as China has done successfully, and Korea and Taiwan before it), and as a job opportunity for non-skilled labour (an aspect all too often forgotten in Europe).

\subsection{From an agricultural to an industrial economy}

Vietnam has successfully mastered the development from food shortages to being one of the bread baskets of Asia and its food processing industry has experienced rapid growth over the past years. However, the benefits from increasing harvests have been unevenly distributed: the privileged members of the Vietnamese society are mostly not from the agricultural sector, but from urban business and service sectors, while farmers themselves are still confronted with low and volatile income for their work. According to our interviews in the Tien Giang province, $94-95 \%$ of the rice production there is consumed locally, only $5-6 \%$ are exported, but the fluctuating price of these 5$6 \%$ strongly influences the price of the $94-95 \%$, and thus the farming income. Some farmers characterised their profession as "hard work, badly paid and with low reputation", but most older farmers, male and female, pledged to 
continue farming as a matter of their social identity. Others keep their farms, but earn most of their income reliably in a comparably short period of working in a factory, often in a nearby city - these "leisure farmers" or "social farmers" enjoy working on the land as part of being a respected member of their local community, but have no incentives to maximise their yield as they live on their (not fluctuating) factory salary. Thus food security concerns add to the previously mentioned reasons for income redistribution.

The highest growth of agricultural production took place in the Mekong delta where rice for the world market is produced using heavy loads of chemical inputs. However, this success came at a high price: high dykes have stopped flooding altogether, allowing 3.5 harvest per year, but requiring massive chemicals use and hard work, which is badly paid (harvests may also be reduced due to a lack of plant available silicon, see [15]). Risks to soil, dyke stability and ecosystem abound, and non-rice food products (fish, shrimps, etc.) are being lost. The dykes also accelerate the river flow, reduce sedimentation and enhance erosion, contributing to a falling water table at a time where climate change and land subsidence threaten the production potential of rice agriculture [7]. The subsidence is caused not least by pumping fossil water from deep aquifers (up to $3 \mathrm{~cm} /$ year in some regions) in the hope to access ground water not contaminated by arsenic. However, as Erban et al. [16] found, deep groundwater extraction is causing interbedded clays to compact and expel water containing dissolved arsenic or arsenicmobilizing solutes (e.g., dissolved organic carbon and competing ions) to deep aquifers over decades. The implication is that deep, untreated groundwater will not necessarily remain a safe source of drinking water. Subsidence leads to salt water intrusions, putting agricultural production at risk even before climate change induced sea level rise leads to the flooding of significant parts of both Vietnam's great deltas, in particular of the Mekong. As if the loss of large fertile areas were not enough (only a limited range can be reused e.g. for shrimp aquaculture and/or by nature based solutions such as the re-use of floating rice), salt water intrusions in the Mekong put one of the world's largest freshwater fisheries at risk, which is already getting under heavy stress from the upstream dam construction plans. A supply alternative for this important protein source is not available, making the risk of under- and malnutrition acute again. As the yield beyond the third harvest is relatively meagre while the input cost is high, lowering dykes, permitting longer periods of flooding might be one cost effective way of slowing such negative trends (of course combined with political efforts to stop upstream countries from causing havoc on the delta region).

In Central and Northern Vietnam, where most farmers produce for the local or the domestic market, harvests are lower, fields are smaller, family farms dominate and farmers are typically 50 years old, and older. In particular, in smaller side arms or in channels the pollution of river water with agrochemicals, and in particular with pesticides is worrying. Locally it is so high that using this water for washing and in particular for cooking and drinking is causing severe health risks (boiling the water before using it eliminates biological risks but increases the concentration of chemicals, and thus the intoxication risk). While formerly widespread contributions to the diet from snails, frogs etc. (in France important delicacies) are no longer available, some species have accumulated enough pesticides for their consumption to be limited to as little as 3 gram per day if the recommendations of the World Health Organisation WHO regarding the Acceptable Daily Intake ADI were respected [3]. Following a government recommendation to prioritise quality over quantity (and thus benefit from higher world market prices for up-market products) in particular larger farmers in the Delta have reacted. For instance, in Tien Giang higher quality has already been tested, in particular by planting Jasmin rice which has already largely replaced Thai rice in Singapore and Malaysia. However, it has limitations of its own: it can only be grown in the dry season. 


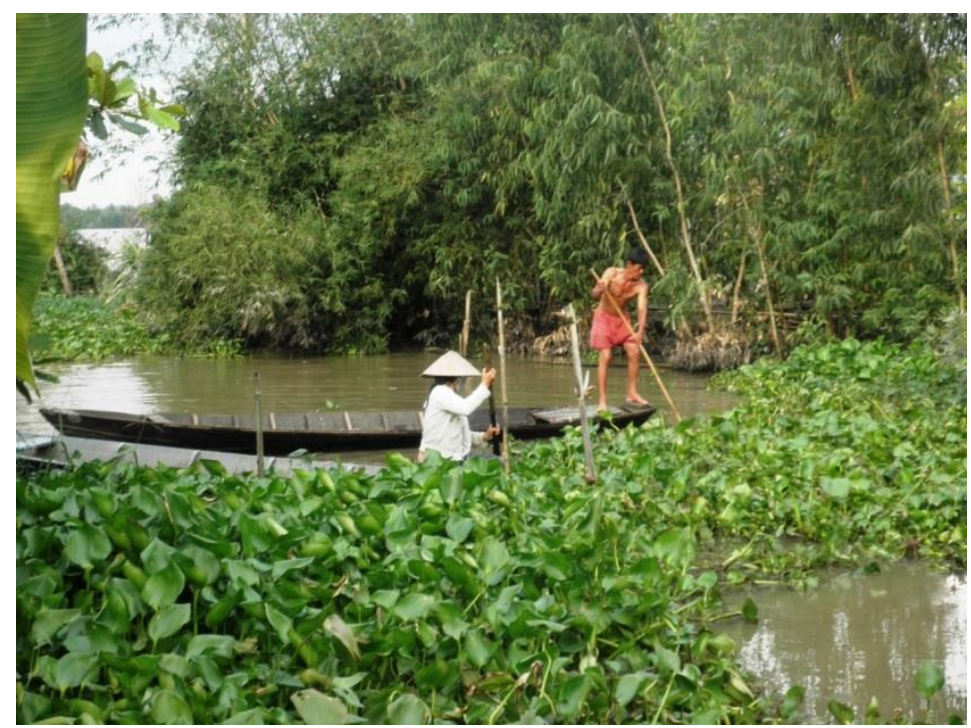

Figure 2. In particular, small streams and canals are highly polluted with pesticides, but still serve as source for washing and food preparation, as workplace and playing ground. Photo: author.

Furthermore, methane, nitrous oxide and ammonia emissions from livestock farming affect environment and health. Truong et al. [17] found that emissions in the Red River Delta are estimated to reach a total global warming potential of $5.9 \mathrm{Mt} \mathrm{CO}_{2 \mathrm{eq}}$ in 2030 (Hanoi contributes for the largest emissions in the region in 2015 but will be surpassed by other provinces in Vietnam by 2030). Lower harvests are partly the result of lacking efficiencies of scale - and partly a result of farmers producing food for the extended family (many of them living in the city) by planting "aromatic" varieties despite their significantly lower productivity of typically some $6 \mathrm{t} / \mathrm{ha}$. Only the rest of the area is used for high yielding varieties (8-11 t/ha) sold on local or regional markets [18]. This is possible due to the family farm management structure - in the South with paid workers on landholders' fields of dozens if not hundreds of hectors, this is almost impossible.

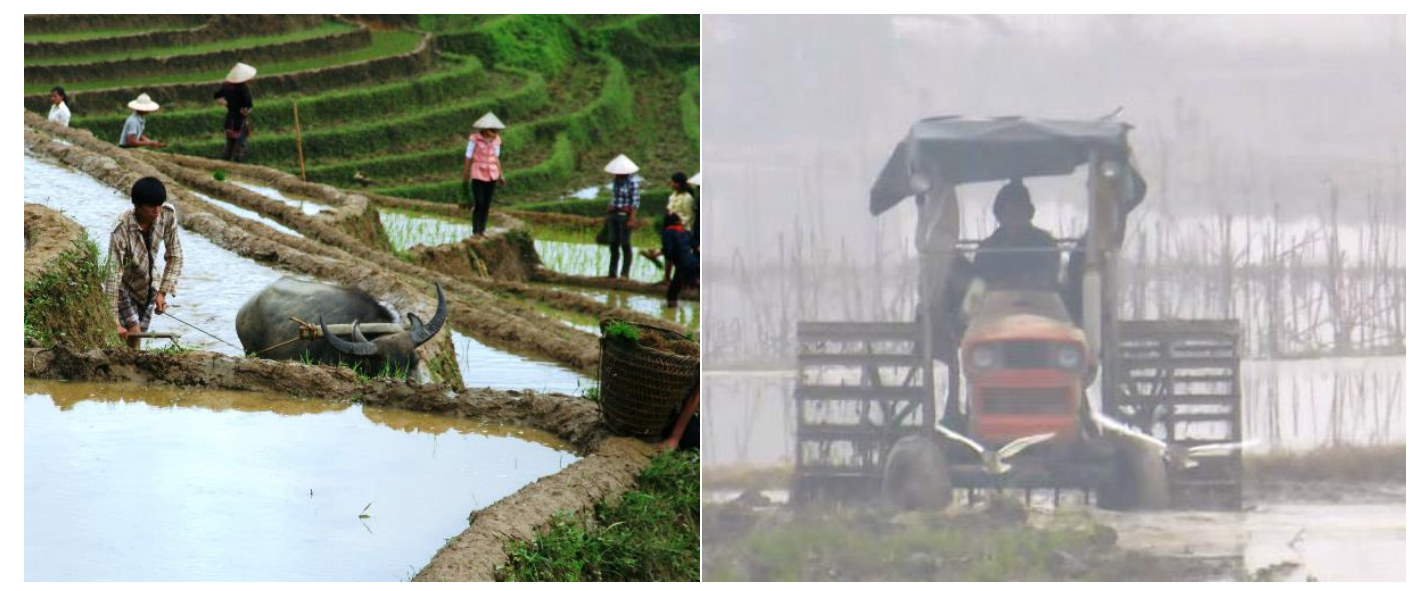

Figure 3: Agricultural modernisation, from water buffalo to mechanic puddler. However, in mountain terrace paddy culture, mechanisation is confronted with limits of terrace stability. Photo: author. 
Technical and planning measures like merging farms to enhance efficiency, and the increased use of mechanical equipment are useful where possible, but are faced with tight limitations due to soil conditions. Paddy agriculture requires an undisturbed dense lower soil layer preventing water loss and making deep ploughing impossible, while the easy compactation of wet soil resulting in reduced fertility limits the use of heavy equipment in wet rice agriculture. In particular in sloping landscape regions where dykes and terraces are needed to stabilise fields the latter limitations become obvious: the larger the fields, the higher the dykes or terraces, and the higher the terrace, the less extra-weight of equipment it can hold.

In the northern uplands the state is taking dramatic steps to (re)configure agricultural production through the introduction and subsidisation of hybrid rice and maize seeds requiring yearly cash investments and access to state supplied inputs. Bonnin and Turner [6] found that such agricultural programmes have resulted in new food insecurities and vulnerabilities overlaying more established concerns. In the border regions, e.g. in Lao Cai province, some indigenous mountain dwellers harvest less than they need to make a living due to an unwelcoming landscape of steep hills, and a climate permitting only one harvest a year; they receive state food support. This risk is amplified by the heritage customs which command dividing up fields (and nowadays use rights) between the children (i.e. not pooling them with one child), resulting in continuously shrinking field sizes and the necessity to construct new terraces in ever less suitable locations (one reason why about a third gets lost every year).

Sufficiently high rice harvests will remain important for Vietnam, first of all for reasons of food security; in the South, high harvest volumes are important to farmers, provinces and the state as they yield significant export earnings. Unfortunately, these achievements are at risk: Food security is under treat from climate change and resistant pests; in particular, farms are threatened by pests like the brown planthopper
(Nilaparvata lugens), the whitebacked planthopper (Sogatella furcifera) and the smaller brown hopper (Laodelphax striatellus) which are increasingly exhibiting resistance to insecticides and adaptation to resistant varieties [19]. As rapidly propagating species with mass invasions, they threaten local and regional food security already in the short to medium run.

In the longer run, the sustainability of rice agro-ecosystems is threatened by continuing climate and land-use changes. Model simulations quantifying future changes of rice production, carbon storage and carbon sequestration under two climate scenarios (until 2100) and three site-specific land-use scenarios (until 2030) for four locations in Vietnam showed reduced carbon fixation and storage, and a decrease in rice yields by approximately $30 \%$ towards the end of the century under the current land-use pattern [20]. However, the results also indicate that land-use change may partially offset the negative climate impacts in regions where cropland expansion is possible, although only at the expense of natural vegetation. Thus land use planning is crucial - transforming agricultural land into industrial zones or selling it to foreign investors who, in the extreme, may concert it to golf courses [5], endangers food security in the medium to longer term. Such land conversion has caused dissatisfaction and hidden conflicts between farmers and planning authorities which despite not breaking into the open due to uneven power potentials, undermine social cohesion and trust [21].

Instead future-proof land management responding to accelerating climate change requires diversity in land use at farm level and along agriculture-forestry landscape gradients to become a key strategy applied by farmers and supported by government. One policy option to support such an approach could include legalization of agroforestry [22], another one is habitat manipulation to enhance biological control in rice, the world's most important crop, to support biological control by strengthening the effectivity of parasitoids of rice pests by supporting biodiversity, and reduce 
agrochemical use (pesticides, fertiliser, seedlings) accordingly [19]. Yet the conservation and reinstatement of biodiversity is challenging, and it has long been suspected that the promotion of biodiversity while reducing reliance on agrochemical inputs, would be penalizing yields on a regional scale. However, as Heong et al. [23] and Gurr et al. [24] have shown, simple measures such as planting of ecological engineering such as nectar-producing plants around rice fields can reduce pesticide applications up to $70 \%$ while increased grain yields by $5 \%$, thus delivering a substantial economic advantage [24]. The problem is not biological, but mental and requires overcoming misperceptions $[23,25]$ and new policy approaches.

A second pillar of sustainable industrialisation is of course the social and environmental standards that apply to industry, and the level of enforcement of any such standards across the different levels of administration. It begins with land grabs which do not pay sufficient attention to the agricultural value of the soil and the value it has to the local population, continues via building permits without proper environmental impact assessment and ends up with sloppy supervision leading to the pollution of land and sea as often reported in the Vietnamese press. While there is significant room for improvement in the performance of government and administration on different levels, there is also a need for better management practices, and for improved monitoring. So far, the national environmental indicator system [26] is way behind what is needed for effective pollution control. Quality management practices have been shown to have positive impact on social performance, while the impacts on economic and environmental performance were mixed, requiring it to be embedded into dedicated competition and Corporate Social Responsibility strategies. The four quality management practices having the most significant positive impact on sustainability performance were top management support for quality management, design for quality, quality data and reporting, and continuous improvement [8].

\subsection{From a rural to an urbanised society}

One driving force of rapid urbanisation is the unwillingness of young people to become farmers, in particular in the family farms in Northern and Central Vietnam. In our interviews farmers told us they advised their children to get education, move to the city and make a different career - and the vast majority planned to follow this advice [18]. Shifting from rice production to more lucrative and (partly) less labour intensive fruits and vegetables can improve the farmers' income situation, but poses another threat to food security. Increasing income will not be enough to stabilise the farming population and slow down the rapid urbanisation: political initiatives are needed to enhance the social standing and the reputation of farmers, e.g. as the "guardians of food security" to overcome the challenge, and reduce the volatility of income from rice production. Attracting more farmers to the countryside remains a social and economic necessity, and a political challenge, despite the process of industrialisation and urbanisation.

The expansion of urban settlement areas as a consequence of these processes not only impinges on the available fertile land for agriculture, but also requires major investments into settlement, water and waste management and transport infrastructure. If settlement growth and infrastructure development are not well coordinated, additional risks to drinking water quality and public health are looming. So far it seems planning is effective but not sustainable, with blue and green infrastructure (decreasing the natural water reservoir and buffering capacity inside the city) playing only a minor role, and the respect for the cultural heritage appears to have limitations. The result is a poor flood prevention infrastructure system in the cities (a critical issue in coastal and delta cities, i.e. almost all major urban settlements) for instance by soil sealing reducing the natural water draining area of the surface, increasing the surface runoff and causing partial flooding of cities. With climate change, this threat will increase in the years to come due to the increasing strength and frequency of flooding. 


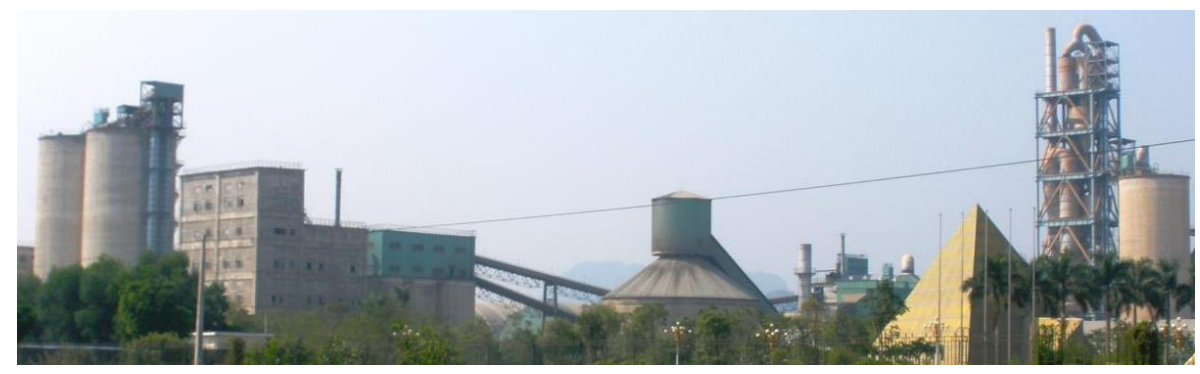

Figure 4. Industrial development near the Red River. Workers can earn as much in a couple of months as they earn from agriculture over the year. However, regarding social and environmental standards there is still significant room for improvement. Photo: author.

A particular challenge to urban development is the increasing level of auto-mobility: whereas motorbikes are a means of transport the urban road system of inner cities can accommodate although having been designed for less people and pedestrian or bike mobility, they cannot deal with a high number of private cars. Ownership levels comparable to Western countries would lead to a complete collapse of transport (as it increasingly does in Europe) which could only be moderated by sacrificing significant shares of the dwellings representing an important part of the Vietnamese cultural heritage (as it has been done in the USA and partly in Europe). Policy initiatives limiting car ownership, or at least accessibility of urban spaces for cars (as in some Scandinavian cities, in London and Paris), are highly recommendable not only for both HCMC and Hanoi, but also for other urban centres.

Urban societies function differently from rural ones - the basic unit of rural social structures are families and neighborhoods, which are closely linked. Urbanisation breaks or at least dilutes these links, family connections remain but fade, while new peer and reference groups emerge, such as professional networks or those based on shared interests. Such networks automatically constitute a civil society, which modifies the patterns of human interaction and the social fabric of the Vietnamese society, a process going on since a number of decades but accelerating more recently. Integrating such civil society dynamics and the re-emerging spiritual and ethical values with the political fabric of the country may be a key element of a future-proof stable development, of good governance for sustainability a la Vietnam. Following a policy analysis approach, Trường et al. [27] identified strengthening the linkages from the policy target group via the policy implementing group to the policy innovation group as the most suitable solution; most probably their insights can be generalised and applied to urban planning processes, beyond the agricultural innovations they analysed.

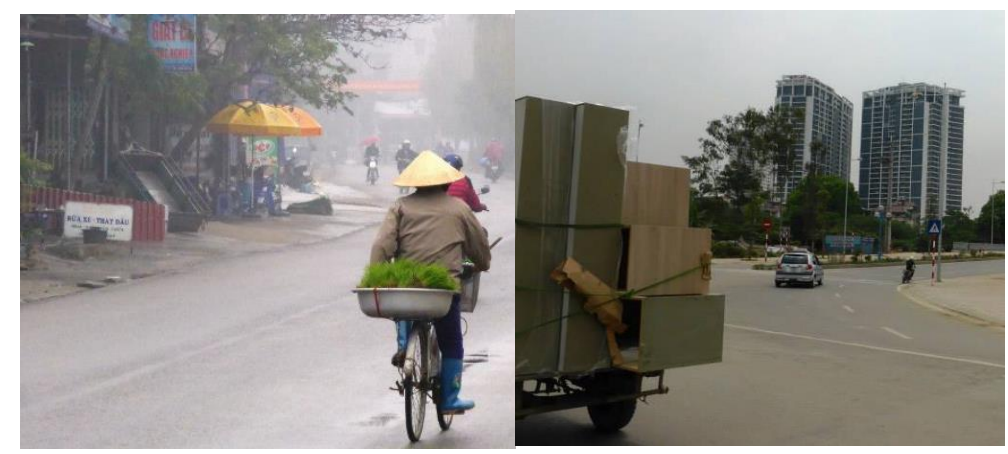

Figure 5. From semi-urban settlement and transport structures with two or three story houses and scooter or bike transport to high rise buildings and motorised mobility. Photos: author. 


\subsection{From a planned to a socialist market economy}

While the market approach has pushed innovation and economic growth, thus contributing to overcoming wide-spread poverty, it has also contributed to social polarisation (as market economies tend to do, see [10]) and eliminated some of the safety nets people could rely upon in earlier times. A climate of fierce competition in all social relations is fuelled by the role of the market as much as by the rapid urbanisation. Members of ethnic minorities complain about the loss of job guarantees, which leaves no other alternative than farm work for some members who successfully finished their academic education (which is an uneconomic use of human capital). Solidarity initiatives, organised by civil society in other countries, receive limited political support and are not necessarily welcome by authorities.

The majority of the population is affected by the necessity to pay for formerly public services such as higher education or health care (with petty corruption increasing the problem and leading to wide-spread dissatisfaction), which they perceive as serious impingements to their quality of life. As there is no inherent law of nature determining which goods should be private, which should be public, which should be merit goods and which should be (free or paid) entitlements for all citizens or inhabitants, every society must make a choice. A socialist market economy will have to make its own choices, which however cannot be imitating the ones of capitalist market societies. In particular, it could be considered if there is room for business models other than state on privately owned, such as foundations, cooperatives and others which do earn profits, but are not bound to maximise them at the expense of public goods.

The USA in particular doesn't offer a suitable role model, although many of the Vietnamese policies of privatising social services appear to be follow the US example. Their system of fully private health care and limited social security provisions for old age, with no support in case of extended diseases and other not self-inflicted situations in which people are handicapped regarding earning a decent salary has led to the highest health care cost together with a shrinking life expectance, well below other affluent countries [28]. Instead an analysis of the diverse social security systems realised in different EU countries (at times when they were less affluent than Vietnam is today) might be helpful to stimulate thinking about a more accommodating system for Vietnam, although they do not lend themselves to be copied in a socialist market economy either. Such inspiration might include considering ending the market relations in some sectors, but could also be the enforcement of market taming rules or collective payment systems, dependent on Vietnamese policy priorities. One condition may be broadening the tax base and enforcing payments by business and wealthy individuals.

One element blurring the dividing line between market goods and public services is corruption; the credibility of any government suffers if efforts to minimise corruption are perceived as absent or failing. Transparency rules for corporations, can be a tool to reduce the risk of corruption (for both domestic and foreign investments), and black lists of companies involved in corruption making them ineligible for contracts with state authorities or licences of all kinds are another one. However, such measures will be hard to implement as long as potential investors experience pressure to bribe, or lose the investment opportunity. This higher level corruption must be tackled, but beyond it the low level, everyday petty corruption of doctors, police, teachers etc.

Economic development will require a solid underpinning by a growing domestic knowledge base, in science, engineering, but also social science and humanities. Regarding the international standing of Vietnamese research and other academic work, one key deficit so far is the language barrier: the scientific world communicates in English, which is admittedly a difficult language for Vietnamese speakers to master. Thus offering training courses by native speakers from different countries is advisable for 
every academic institution, as is a pool of experienced English speakers which checks and improves every English language manuscript before submission for publication. Guest teachers lecturing in English would prepare students for participating in the global research agenda, and the language skills of Vietnamese English teachers deserve some improvement.

This would also be a condition for engaging with those research issues en vogue in the international academic community, in particular in the basic and applied environmental and sustainable development research. While not necessarily focussed directly on domestic applicability, such research can lay the ground for future applications and is a key condition for Vietnamese researchers to play a more prominent role in the international research community. The large Vietnamese diaspora and the researchers of Vietnamese origin evolving from it may provide a bridge towards this step towards internationally recognised research excellence.

2.5. From a rather steady state of environmental conditions to a rapidly changing climate and environment

Vietnam is one of the countries which will be hardest hit by climate change: more frequent and stronger typhoons threaten all coastal regions, and rainstorms of increasing strength the mountain regions. Sea level rise threats have been long underestimated, in particular as the last IPCC predicted a rise of about $1 \mathrm{~m}$ by the end of the century [29] which appeared challenging but somehow manageable (although risky for HCMC). However, the latest expectations regarding sea level rise, taking into account new data from Greenland and Antarctica and the thermic expansion of the oceans by far surpass this estimate - to be on the safe side, it should at least be doubled, taking precaution into account as it may be higher than the global average (like in the past) in the Vietnamese East Sea. With about $2 \mathrm{~m}$ by 2100 , and the higher top speeds of storms, sea level rise threatens $3 / 4$ of the area of HCMC, some $4 / 5$ of the agricultural area in the Mekong delta, and up to $1 / 3$ of the agricultural area in the Red River delta. While some nature based solutions such as revitalising mangrove forests can help against the most damaging effects of tsunamis and typhoons, there is no way to escape the effects of sea level rise, exacerbated by the land subsidence described earlier. While some major cities in affluent countries like New York or London have been considering building dykes around their cities, huge technical installations fail on the soft ground of deltas in Vietnam, as everywhere in the world under comparable conditions (leaving cost arguments aside for the time being), and emergency planning needs to be drawn up and enforced rather immediately. In the UK, for instance, new building permits are only issued on the inwards side of settlements, making urban areas slowly retreat from the risky coast (a rule established in the USA in the 1970s, but abolished by the Reagan administration - it would have mitigated their current problems).

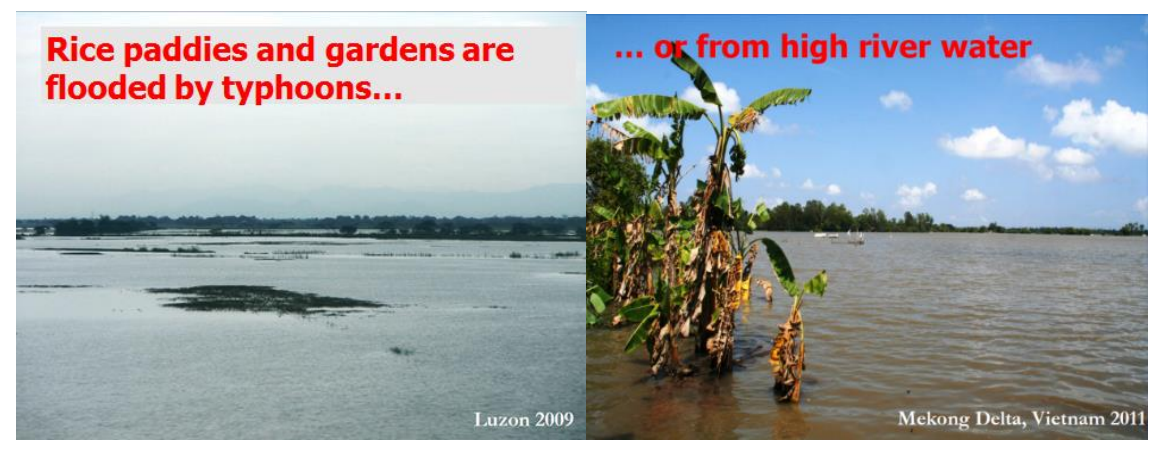

Figure 6. Freshwater floods in lowland agricultural areas, which will become stronger and more frequent in the future. Photos: author. 
Yet it is not only salt water intrusions putting the Vietnamese bread basket at risk, the fresh water contributes to the challenge as well. The Mekong River upstream flooding coinciding with a high tide regime in the East Sea, and the timing and scale of rains imply that more heavy floods occur in the cities more frequently (hence the Chinese efforts - with limited success so far - to build "sponge cities"). A study in Can Tho City found that in addition to damages to the city's infrastructure, the floods also affected residents' livelihoods as during flooding, nearly half of respondents' houses were inundated heavily at $20-50 \mathrm{~cm}$. More than three-quarters of respondents thought that urban flooding had become a very serious issue over the last five years, and half of respondents thought it would continue to be so for the next ten years [30].

Sea level rise is particular dangerous as it combines with on-land developments; the contributions from urban planning and ground water extraction leading to subsidence have already been mentioned. Add to this the short term, human-made challenges of dams being built in Laos and China, and the long term impacts of climate change, and a rather gloomy picture emerges. However, additional - and maybe still larger - threats are emerging upstream, as a result of climate change. The Hindu Kush Himalaya mountain range, where Asia's great rivers including the Mekong originate, is undergoing dramatic changes. Today glacier ice serves as a temporary water buffer, fixing it as snow and ice in the winter but releasing it from spring to summer when it is most needed for agriculture downstream, thus providing a more regular flow and avoiding periods of water scarcity. This will change in the longer term: already a third of the mountain ice has been lost, and experts expect a loss of up to two thirds by the end of the century [31]. And even this may be an underestimation of the changes to be expected and the speed with which they will arrive as the most recent research shows that the change in the mountains is accelerating [32].
In such a situation of increasing stress on natural systems, strengthening their resilience is an imperative since despite the great diversity of livelihoods and ecosystems in the country, the sectors of agriculture, livestock, fisheries, nontimber forest products and rural infrastructure have one thing in common - their resilience to climate change is dependent on healthy, functioning natural ecosystems [33]. The most fundamental element of adaptation strategies must be bringing diversity and complexity back into the agricultural landscape. Increased diversity in farming ecosystems means a broader range of species and a deeper genetic pool. Increased complexity means more mutually beneficial relationships and synergies between those components and farm diversification aims to maintain an optimal level of overall production and return. "Another closely linked principle for adaptation is optimising biodiversity in farming. That principle means more than increasing the range and number of crops grown on a farm - although that is critical for stability in output. It is about the overall enhancement and maintenance of ecosystem health on farms and their surrounding areas and catchments" [33] not least to support biocontrol and reduce pest damages while using much less pesticides, plus less fertiliser and seedlings without reducing the harvest [24].

However, in Vietnam the opposite has happened: with the promotion of high yielding varies, traditional ones have been lost and the gene pool has been shrinking. Forest degradation has led to additional loss of biodiversity, as has water pollution, insensitive urbanisation, unsustainable and not well-planned coastal and rural development including infrastructure such as roads, industries and mining. Careful land use planning, coherent and enforced, short, medium and longer term, is one of the most important tools to mitigate these developments. While small holder farmers in particular in the Mekong Delta have proven to be extremely diverse and flexible the trends are for consolidation of holdings and a shift to highly productive monocultures. Farm diversification is a key 
principle which needs to guide climate change adaptation in agriculture. "Promoting diversity and complexity in farming ecosystems will require compromises on the nature, pace and scale of development across many sectors. It means taking a more cautious approach which avoids and compensates for degrading natural systems" [33].

\section{Outlook}

\subsection{Understanding the challenges}

One problem for longer-term policy planning is that the current challenges are new, and hardly any experience is available how to best deal with them. Another challenge is that they appear simultaneously and with combined effects, which makes any prediction even more difficult. So the first necessity is to learn distinguishing between apparent problems and their drivers to develop policies which are not only addressing symptoms but the causes of problems.

In Europe, the Environment Agency and the Statitical Office use a scheme called DPSIR (Drivers, Pressures, State, Impact, Reponse) to visualise these relations (IPBES, the Intergovernmental Science-Policy Platform on Biodiversity and Ecosystem Services, calls
Driver "indirect Drivers" and Pressures "direct Drivers") [14]. If impacts are unavoidable and changes irreversible, adaptation is necessary (and if at all possible with foresight, like building dykes), while reversible changes of the state can be addresed by restoration measures like reforestation or re-establishing mangrove forests as it is happening all over the Vietnamese coast. Both may be urgent and have to be undertaken immediately, but both will not overcome the problem: as long as Pressures and Drivers continue to be effective, once solved problems will reappear, albeit possibly in a modified form.

Thus mitigating Pressures (= direct Drivers in IPBES parlance) is necessary to provide relief and end the pressure on the State as it is. However, even this is not enough: as long as the (indirect) Drivers are not changed, Pressures will build up again. Thus policy planning must define objectives, identify the Drivers preventing success, and overcome them by redirecting the Drivers towards benign purposes - obviously an issue of structural change in society and economy in need of careful planning, room for experimentation and courageous action. It should be mentioned that the responsibility for the different kinds of Responses may be attributed to different administrative levels, with Prevention usually in the competence of the top level decision makers.

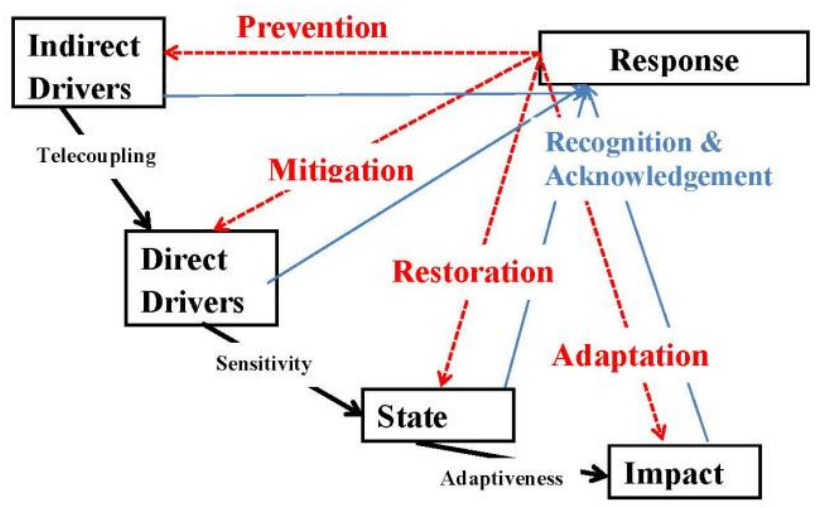

Figure 7. Different problems, different responses: the DPSIR heuristic. Source: author. 


\subsection{Institutions for change}

The question then is one about agency: who are the actors relevant for such proactive policy development? According to political theory we may distinguish three levels of institutions (set of rules) on which tey are located; we thus differentiate the Drivers into primary, secondary and tertiary ones attributed to the three levels of institutions.

- Organisations (associations, clubs, parties,...) implement rules, but also develop them and are structured and guided by rules such as bylaws, constitutions, mandates etc. They can have a high degree of inertia (i.e. resistance against rule changes) which makes them both indispesible tols of implementing change and a potential obstancle to such change.

- Mechanisms are the second level, processes in policies, government and economy, including the rules of decision making. Laws and regulations, but also informal codes of conduct and power relations are prominent examples: they set the goals and the means to pursue them for the organisations, but are also shaped by the organisations. Mechanisms should be reliable and transparent to generate a feeling of trust and security amongst those who have to follow the rules; unclear regulations or rules which are frequently broken become ineffective and invite circumventing them e.g. by corruption. A transition to sustainability as described by the SDGs will require adapting the prevailing rules to this vision, and restructure organisations accordingly.

- The third level of institutions are orientations, the overarching goals of a society, including its ideas of progress and justice, attitudes towards nature and the public good, ideologies and other bodies of ideas orienting human desires and preferences.

Whereas mechansims and organisations can relatively easily be changed by political decisions (if properly implemented), orientations pose a problem to decision makers pursuing change: while restricting what is politically possible without provoking resistance and unrest on the side of those affected, they are at the same time hard to reshape politically. They evolve through social processes and communication, but can also change abruptly as a consequence of deep shock events.

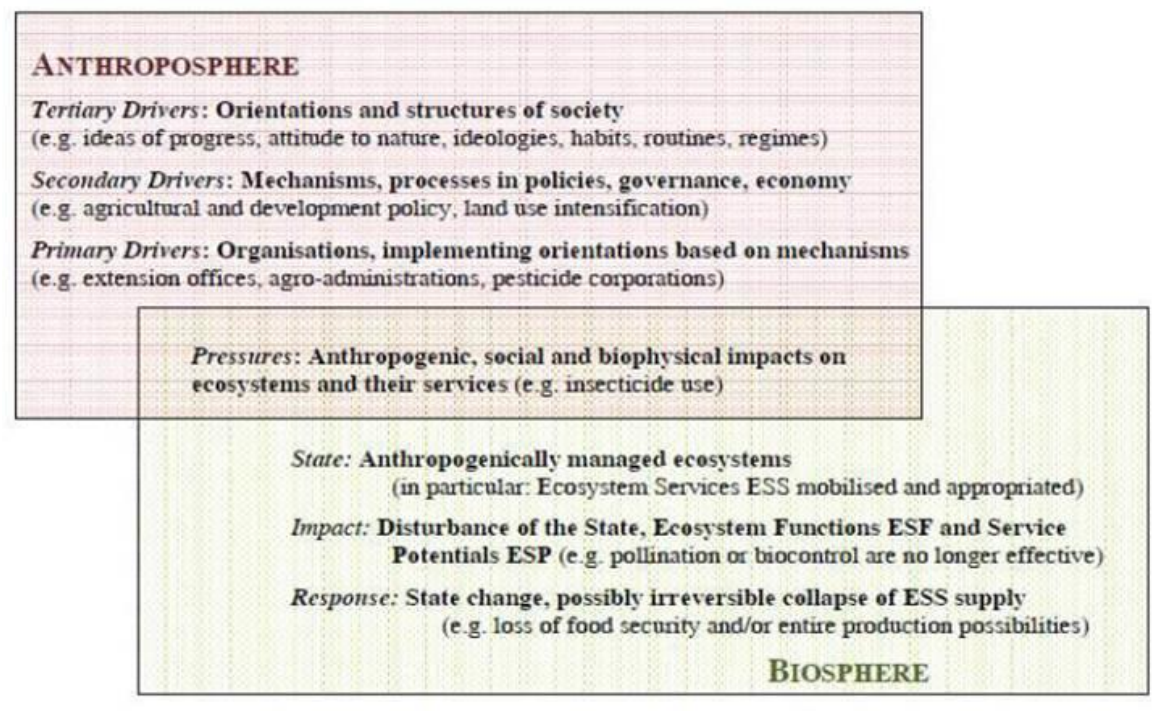

Figure 8. Drivers unpacked: the institutions accommodating them. While this scheme is for the impact on environmental change, the same exercise can be undertaken for social change, changing not the hierarchy and the levels of institution, but only the examples chosen to illustrate them. Source: author. 
Consequently, addressing the Drivers is a delicate balancing act. However, orientations are not free from external influences - knowledge, discourses and daily routines, even if initially taken up involuntarily, feed back on the orientations. Social practices, once established, shape the orientations as much as they are shaped by them. Thus change on this level will be the result of combined pull and push efforts to stimulate the evolution of orientations, and to make them accommodate the changes required.

Another challenge is that some of the Drivers are not under domestic policy control - neither global markets not the size and speed of climate change can be managed domestically. In these cases, proactive adaptation has to play a major role, but be combined with contributions to global efforts to keep the problems in check (regarding climate change for instance, switching from coal to renewable energies would not only be a contribution to global efforts, but would also be supportive for Vietnam to receive climate adaptation funding from the Paris Accord funding mechanisms).

\subsection{Policy reaction examples combining adaptation and mitigation}

As a result of the new challenges, innovative adaptation strategies are required, in agriculture, industrial development, and economic and social planning, taking the effects of all three levels of institutions into account.

For instance, to safeguard the nutritional base of Vietnam, the farming sector needs major changes towards diversification, reduced pesticide use to safeguard drinking water quality, and reliable remuneration to attract a sufficient workforce to the farming sector. Improving the reputation of farmers will be more difficult than increasing their income, but public media, political honours for frontrunners and overachievers, and the involvement of farming communities in decision preparation processes affecting them may be means to change the prevailing perception. A large-scale shift to organic rice production could significantly increase the value surplus per hectare, thus solving part of the flooding problem for the export sector (although not for domestic supply, as for feeding the population the value has to be measured in calories, not in Dong). So far, despite government support, the sector is still limited, not least as the trust in organic or pesticide-free labels has been undermined by past experience (the mechanisms have not worked properly, as the were not stringently enforced by the organisations, maybe for a lack of competence, lazyness or corruption).

In energy policy, a change of priorities is urgent: If due the Paris Climate Accord fossil fuelled power plants have to be phased out completely by the midst of the century, building new ones today means they are going to end up as stranded assets, or they will testify the country's violation of the Paris agreement. It is easy to predict that those countries in flagrant breach may have difficulties in getting their share of the transition aid expected to become available under the Paris Accord (although a few major countries use their power position to ignore the treats and their responsibilities). Adaptation to and mitigation of climate impacts will require additional efforts, including restoration projects, from reducing groundwater abstraction in the Mekong Delta to coastal protection and agreements with upstream countries on water use.

This example shows that necessary adaptation, restoration and mitigation efforts risk ending up nowhere if not combined with prevention approaches, for logic of causal relations as much as for the logic of international financial flows.

\subsection{Triangulation}

Stakeholder dialogues on all levels validating information by using independent sources is known in science as triangulation. Successful policy development must be based on reliable information, but the more complex a society becomes in the development process, the more information is dispersed. As our interviews 
in several provinces have shown, official information collection filters unpleasant results and hesitates to report underachievement to the next higher level of administration. The information reaching the top level has undergone several such selection processes and may not be the best possible basis for decision making. Thus effective governance requires additional, but independent sources of information (as otherwise the validation would be futile); the emerging civil society, in particular in urban areas, could be one useful source of such information. Acknowledging this role and their usefulness for better governance would affiliate them with the overall development in a more harmonious relationship than scepticism.

\section{Conclusions in a nutshell}

Ultimately implementing the UN 2030 Agenda and its Sustainable Development Goals [1], which has been endorsed by Vietnam together with almost all other countries, poses a massive challenge and requires a balanced approach reconciling social, economic and environmental criteria. It requires making use of the full spectrum of measures, from adaptation via restoration to mitigation and prevention, and in order to achieve that, increasing flexibility of organisations, adaptation of mechanisms where necessary, without risking reliability and transparency, and the incorporation of the SDGs as "object of desire" into the orientations of the Vietnamese society.

However, doing so is not only a necessity due to international obligations, but also in the best interest of the country and its people. Quality in production and consumption (including organic rice agriculture), education, transparency, social sustainability and distribution may be key elements of a sustainable future for Vietnam, and important elements of a steadily improving standard of living (which is a much broader policy objective, and now that poverty is almost eliminated, more appropriate than mere income growth). This is a huge challenge indeed, but not the first one Vietnam has mastered with bravery.

\section{Acknowledgements}

The author is grateful to his colleagues in the LEGATO project and the staff of IPAM, the Institute of Policy and Management at the VNUUniversity of Social Sciences and Humanities, Hanoi; in particular Dao Thanh Truong and Nguyen Thi Quynh Anh for their cooperation and support, which enabled him to learn about Vietnam. Repeated invitations by the Rosa Luxemburg Foundation helped adding to the understanding.

\section{References}

[1] United Nations General Assembly, Transforming our world: the 2030 Agenda for Sustainable Development, Resolution 70/1 adopted by the General Assembly on 25 September 2015. Document A/RES/70/1. United Nations, New York, 17th session, Agenda items 15 and 116, 2015.

[2] J. Weeks, N. Thang, R. Roy, J. Lim, Seeking Equity within Growth. The Asia-Pacific Regional Programme on Macroeconomics of Poverty Reduction. UNDP Regional Bureau for Asia and the Pacific. Ha Noi, 2004.

[3] P.M. Hoai, Z. Sebesvari, T.B. Minh, P.H. Viet, F.G. Renaud, Pesticide pollution in agricultural areas of Northern Vietnam: Case study in Hoang Liet and Minh Dai communes, Environmental Pollution 159(12) (2011) 3344-3350.

[4] Worldbank, PovcalNet, http://iresearch.worldbank.org/Povcal.Net/index.h tm?0, accessed September 6th, 2016.

[5] P. Daum, Reisfelder zu Golfplätzen, Le Monde diplomatique 2019(2)(2019) 14-15.

[6] C. Bonnin, S. Turner, At what price rice? Food security, livelihood vulnerability, and state interventions in upland northern Vietnam, Geoforum 43(1)(2012) 95-105.

[7] C.A. Howie, Dike Building and multiple rice crops in An Giang Province, Vietnam: benefits, losses and future risks? Paper presented at the ESP Conference Bali, Indonesia, August 26th - 30th, 2013, Ecosystem Services Partnership ESP 2013. 
[8] N.M. Hue, P.A. Chi, Y. Matsui, Contribution of Quality Management Practices to Sustainability Performance of Vietnamese Firms, Sustainability 10 (2) (2018) 375. https://doi.org/10.3390/su10020375.

[9] J.A. Schumpeter, The Instability of Capitalism, The Economic Journal 38(1928) 361-386.

[10] T. Piketty, Capital in the Twenty-first Century, Harvard University Press, Boston, USA, 2014.

[11] Vietnam Investment Review May 27 -June 2, Focus "Sustainable actions", 1 (2019) 4-21.

[12] KOPO, Smart Grids: Was kosten die intelligenten Netze der Zukunft?, Kommunalpolitische Blätter 14.06.,

2012. https://kopo.de/blog/2012/06/14/smart-grids-waskosten-die-intelligenten-netze-der-zukunft/, accessed June 20th, 2019.

[13] UBA Umweltbundesamt (Federal Environment Agency), Emissionen des Verkehrs. https://www.umweltbundesamt.de/daten/verkehr/e missionen-des-verkehrs\#textpart-1 of May 31st, 2019, accessed July $20^{\text {th }}, 2019$.

[14] IPBES Intergovernmental Science-Policy Platform on Biodiversity and Ecosystem Services, Brondizio, E.S., Díaz, S., Settele, J., The IPBES Global Assessment on Biodiversity and Ecosystem Services, Secretariat of the Intergovernmental Science-Policy Platform on Biodiversity and Ecosystem Services, Bonn, Germany, 2019.

[15] T. Klotzbücher, A. Marxen, D. Vetterlein, J. Schneiker, M. Türke, N. van Sinh, N.H. Manh, H. van Chien, L. Marquez, S. Villareal, J.V. Bustamante, R. Jahn, Plant-available silicon in paddy soils as a key factor for sustainable rice production in Southeast Asia, Basic and Applied Ecology 16(8)( 2015) 665-673.

[16] L.E. Erban, S.M. Gorelick, H.A. Zebker, S. Fendorf, Release of arsenic to deep groundwater in the Mekong Delta, Vietnam, linked to pumpinginduced land subsidence, Proceedings of the National Academy of Sciences 110(34)(2013) 13751-13756.

[17] T.A. Ha, K.M. Thuy, N.T. Thu, N.N. Tung, N.Q. Trung, Methane, Nitrous Oxide and Ammonia Emissions from Livestock Farming in the Red River Delta, Vietnam: An Inventory and Projection for 2000-2030. Sustainability 10(10), (2018) 3826. https://doi.org/10.3390/su10103826

[18] J.H. Spangenberg, A.L. Beaurepaire, E. Bergmeier, B. Burkhard, Ho Van Chien, Le Quoc Cuong, C. Görg, V. Grescho, Le Huu Hai, K.L. Heong, F.G. Horgan, S. Hotes, A. Klotzbücher, T. Klotzbücher, I. Kühn, F. Langerwisch, G. Marion, R.F.A.
Moritz, N.T.Q. Anh, J. Ott, C. Sann, C. Sattler, M. Schädler, A. Schmidt, V. Tekken, D.T. Truong, K. Thonicke, M. Türke, T. Vaclavik, D. Vetterlein, C. Westphal, M. Wiemers, J. Settele, The LEGATO cross-disciplinary integrated ecosystem service research framework: an example of integrating research results from the analysis of global change impacts and the social, cultural and economic system dynamics of irrigated rice production. Paddy and Water Environment PAWE 16(2)(2018) 287-319.https://doi.org/10.1007/s10333-017-0628-5.

[19] G.M. Gurr, J. Liu, D.M.Y. Read, J.L.A. Catindig, J.A. Cheng, L.P. Lan, K.L. Heong, Parasitoids of Asian rice planthopper (Hemiptera: Delphacidae) pests and prospects for enhancing biological control by ecological engineering. Annals of Applied Biology 158(2) (2010) 149-176.

[20] Langerwisch, F., Vaclavik, T., Bloh, W. v., Vetter, T.Thonicke, K., 2017, Combined effects of climate and land-use change on the provision of ecosystem services in rice agro-ecosystems, Environmental Research Letters 13(1), 015003. https://doi.org/10.1088/1748-9326/aa954d.

[21] J.H. Spangenberg, K-L- Heong, A. Klotzbücher, T. Klotzbücher, N.T.Q. Anh, V. Tekken, D.T. Truong, M. Türke, J. Settele J., Doing what with whom? Stakeholder analysis in a large transdisciplinary research project in South-East Asia, Paddy and Water Environment PAWE 16(2)(2018) 321-337. https://doi.org/10.1007/s10333-018-0634-2.

[22] M.H. Hoang, S. Namirembe, M. van Noordwijk, D. Catacutan, I. Öborn, A.S. Perez-Teran, H.Q. Nguyen, M.K. Dumas-Johansen, Farmer portfolios, strategic diversity management and climate-change adaptation - implications for policy in Vietnam and Kenya, Climate and Development 6(2)(214) 1-10.

[23] K.L. Heong, L. Wong, J.H, de los Reyes, J. H., Addressing Planthopper Threats to Asian Rice Farming and Food Security: Fixing Insecticide Misuse, in: K.L. Heong, J. Cheng, M.M. Escalada (Eds), Rice Planthoppers: Ecology, Management, Socio Economics and Policy. Zhejiang University Press \& Springer Science+Business Media, Hangzhou, China and Dordrecht, NL, 2015, 69 - 80.

[24] G.M. Gurr, Z. Lu, H. Xu, P. Zhu, G. Chen, X. Yao, J. Cheng, Z. Zhu, J. L. Catindig, S. Villareal, H.V. Chien, L.Q. Cuong, C. Channoo, N. Chengwattana, L.P. Lan, L.H. Hai, J. Chaiwong, H.I. Nicol, D.J. Perovic, S.D. Wratten, K.L. Heong, Multi-country evidence that crop diversification promotes ecological intensification of agriculture. 
Nature Plants 2(2016), 16014. https://doi.org/10.1038/nplants.2016.14.

[25] J.H. Spangenberg, J.-M. Douguet, J. Settele, K.L. Heong, Locked Into Continuous Insecticide Spraying in Rice. Developing an integrated ecological and socio-political DPSIR analysis, J Ecological Modelling 295(2015) 188-195, http://dx.doi.org/10.1016/j.ecolmodel.2014.05.010

[26] N. Phong, V.T. Thuy, A., Sookun, The application of the Framework for the Development of Environment Statistics (FDES 2013) in Vietnam, ENVSTATS News and Notes 34(2013) 19-20.

[27] D.T. Truong, N.T.Q. Anh, N.T.N. Anh, Đ.K.K Ly, J.H. Spangenberg, J. Settele, V. Tekken, B. Rodríguez-Labajos, Policy Analysis Approaches in Implementing the Ecological Engineering in Vietnam: Experiences from LEGATO - An Interdisciplinary Project, VNU Journal of Science: Policy and Management Studies 32(1) (2016) 49-67.

[28] Speth JG. 2019, A People's State of the Nation. Common Dreams, March 29, 2019, https://voicesmotherearth.blogspot.com/2019/04/a -peoples-state-of-nation.html.

[29] IPCC Intergovernmental Panel on Climate Change, Climate Change 2014: Impacts, Adaptation, and
Vulnerability, IMO, UNEP, New York, Nairobi, 2014.

[30] T.D. Vo, Household economic losses of urban flooding, Case study of Can Tho City, Vietnam. Asian Cities Climate Resilience Working Paper Series 12. International Institute for Environment and Development (IIED), London, UK, 2014.

[31] P. Wester, A. Mishra, A. Mukherji, A.B. Shrestha, A. B. (Eds), The Hindu Kush Himalaya Assessment: Mountains, Climate Change, Sustainability and People, Springer Nature Switzerland Cham, Switzerland, 2019.

[32] J.M. Maurer, J.M. Schaefer, S. Rupper, A. Corley, Acceleration of ice loss across the Himalayas over the past 40 years. Science Advances, 5(6), (2019). eaav7266.

https://doi.org/10.1126/sciadv.aav7266

[33] J. Carew, L. Reid, L. Taylor, Natural Systems and Climate Change Resilience in the Lower Mekong Basin: Future directions for biodiversity, agriculture and livelihoods in a rapidly changing environment, International Centre for Environmental Management ICEM, Hanoi, Vietnam, 2014. 